Supplement of Nat. Hazards Earth Syst. Sci., 17, 115-125, 2017

http://www.nat-hazards-earth-syst-sci.net/17/115/2017/

doi:10.5194/nhess-17-115-2017-supplement

(C) Author(s) 2017. CC Attribution 3.0 License.

(c) (1)

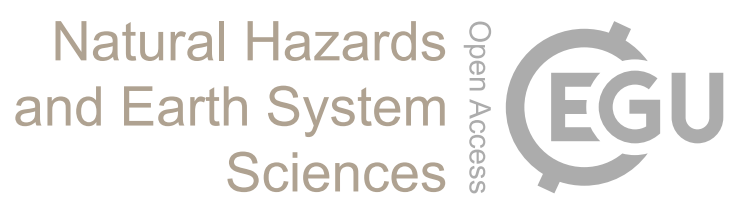

Supplement of

\title{
Heat waves in Africa 1981-2015, observations and reanalysis
}

Guido Ceccherini et al.

Correspondence to: Guido Ceccherini (guido.ceccherini@ext.jrc.ec.europa.eu)

The copyright of individual parts of the supplement might differ from the CC-BY 3.0 licence. 
Annex:
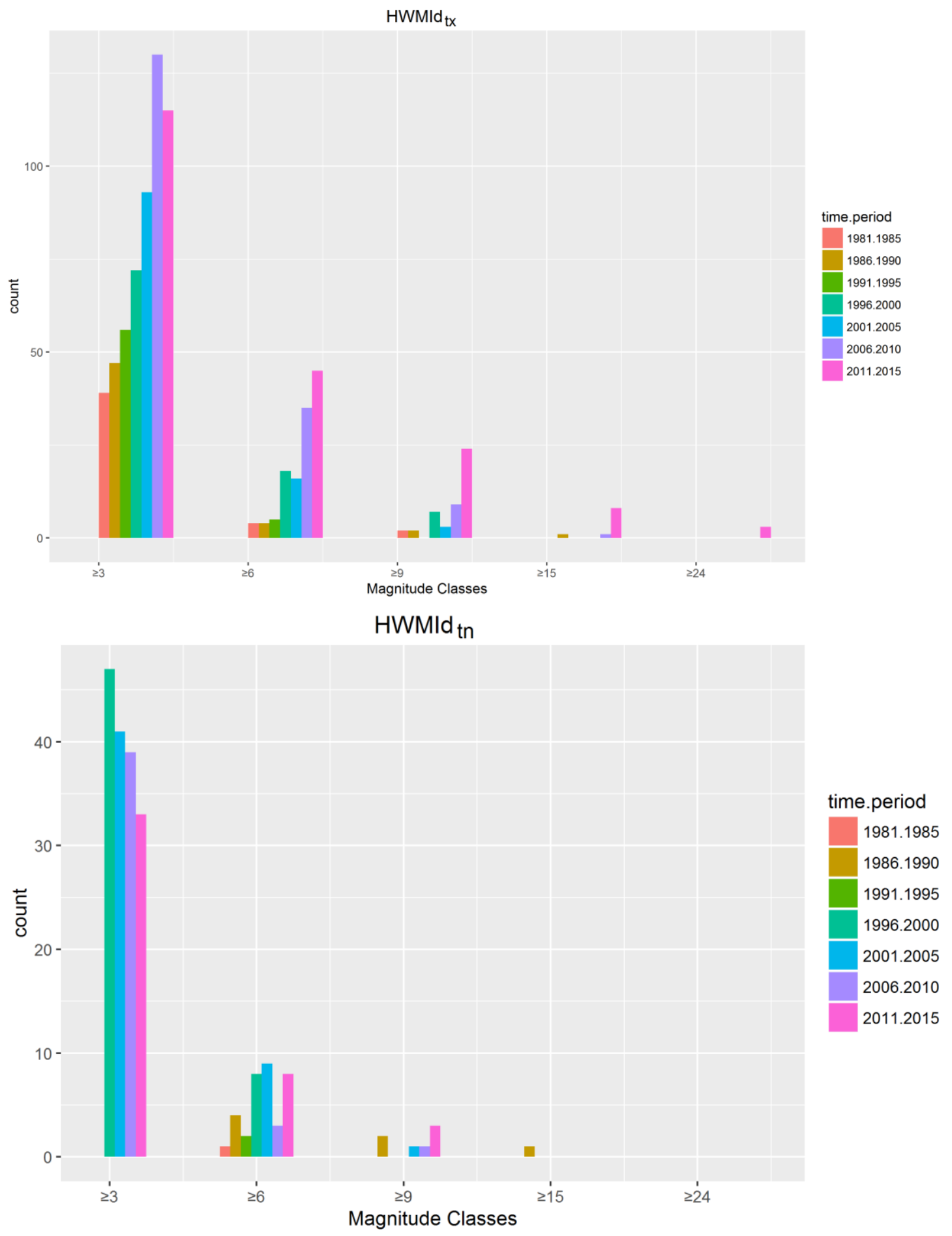

Figure S1 Histogram of heat wave of maximum (tx, upper panel) and minimum (tn, bottom panel) temperature for 5-year period of GSOD records during 1981-2015. 

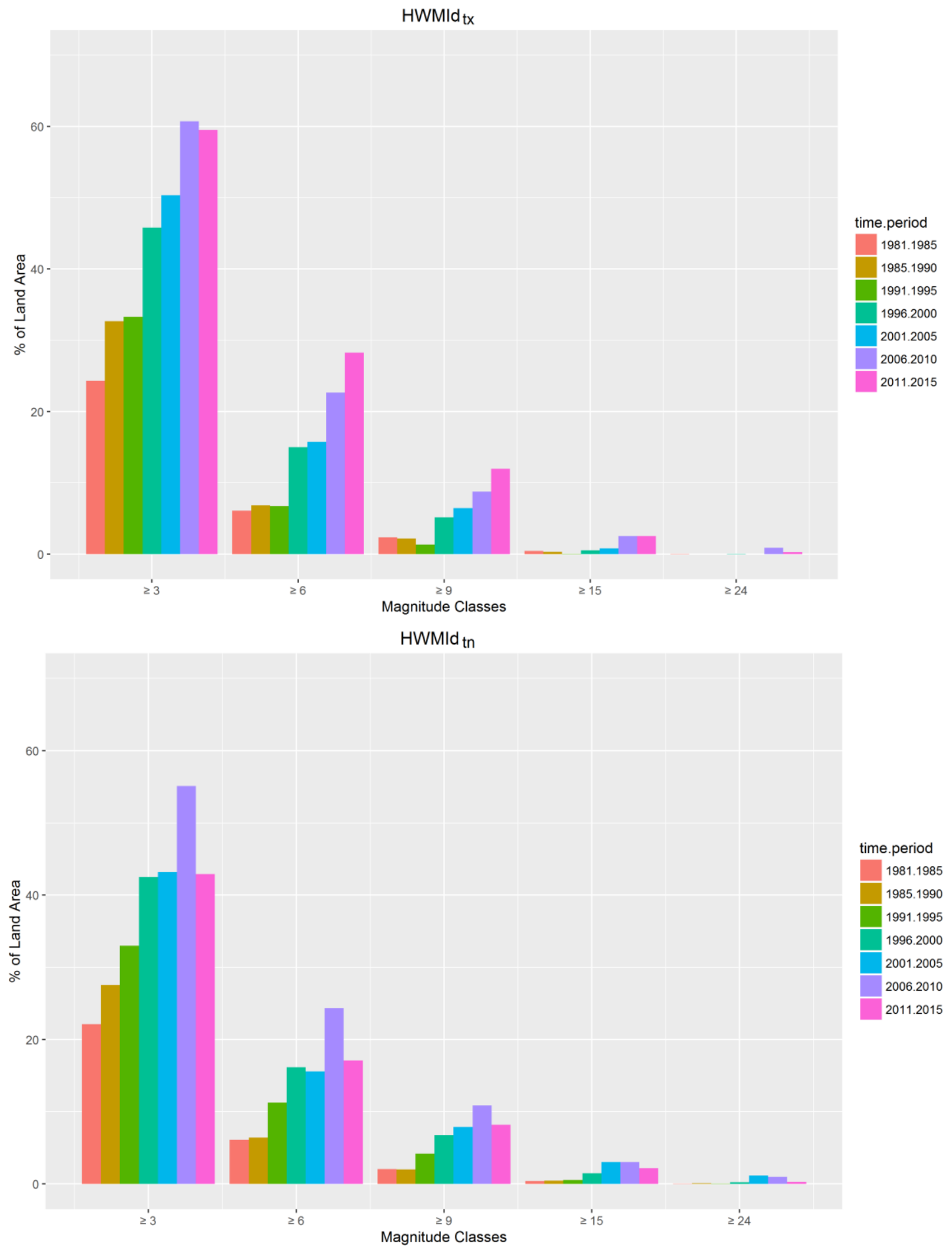

Figure S2 Histogram of heat wave of maximum (tx, upper panel) and minimum (tn, bottom panel) temperature for 5-year period of ERA-INTERIM dataset during 1981-2015. 

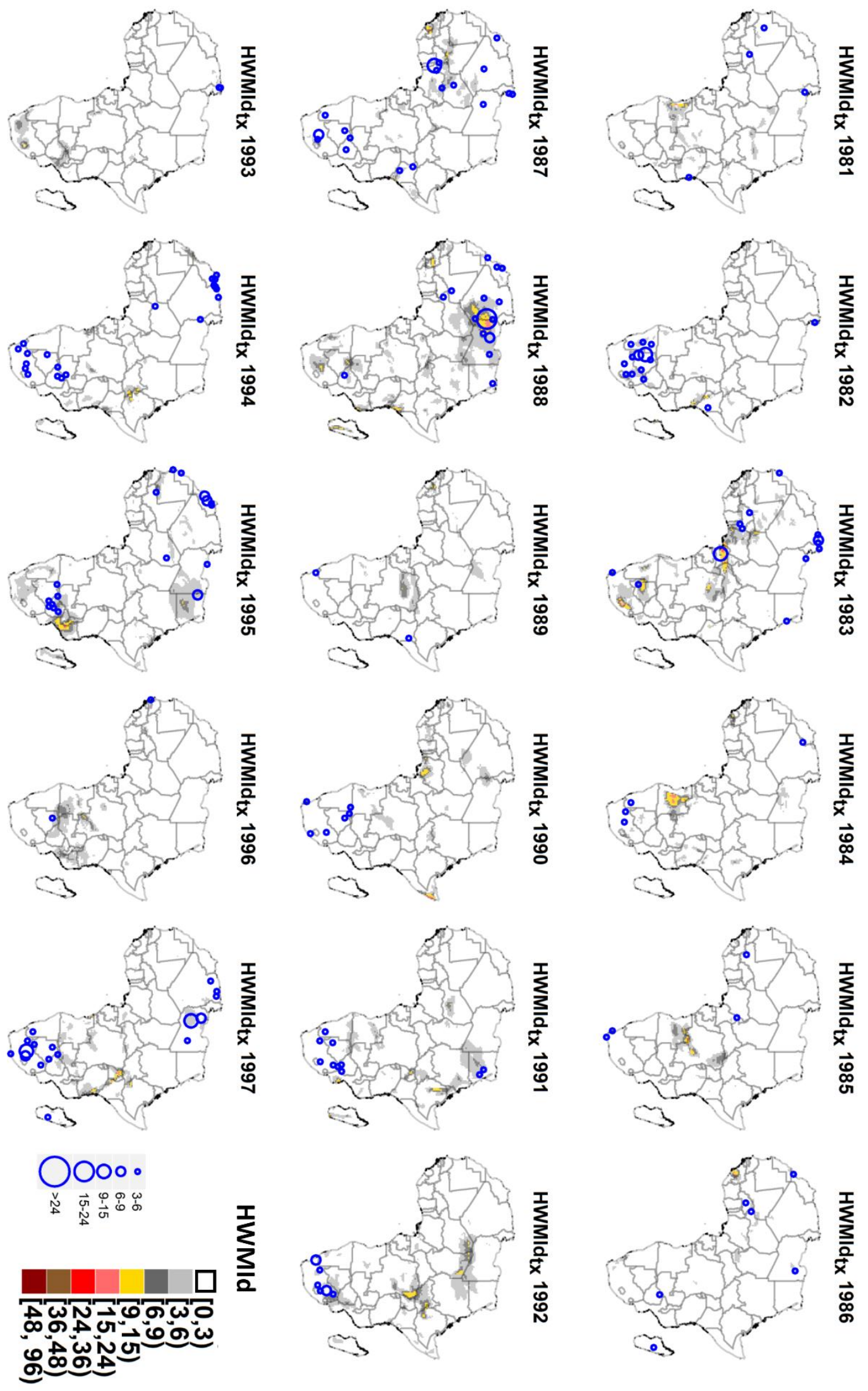

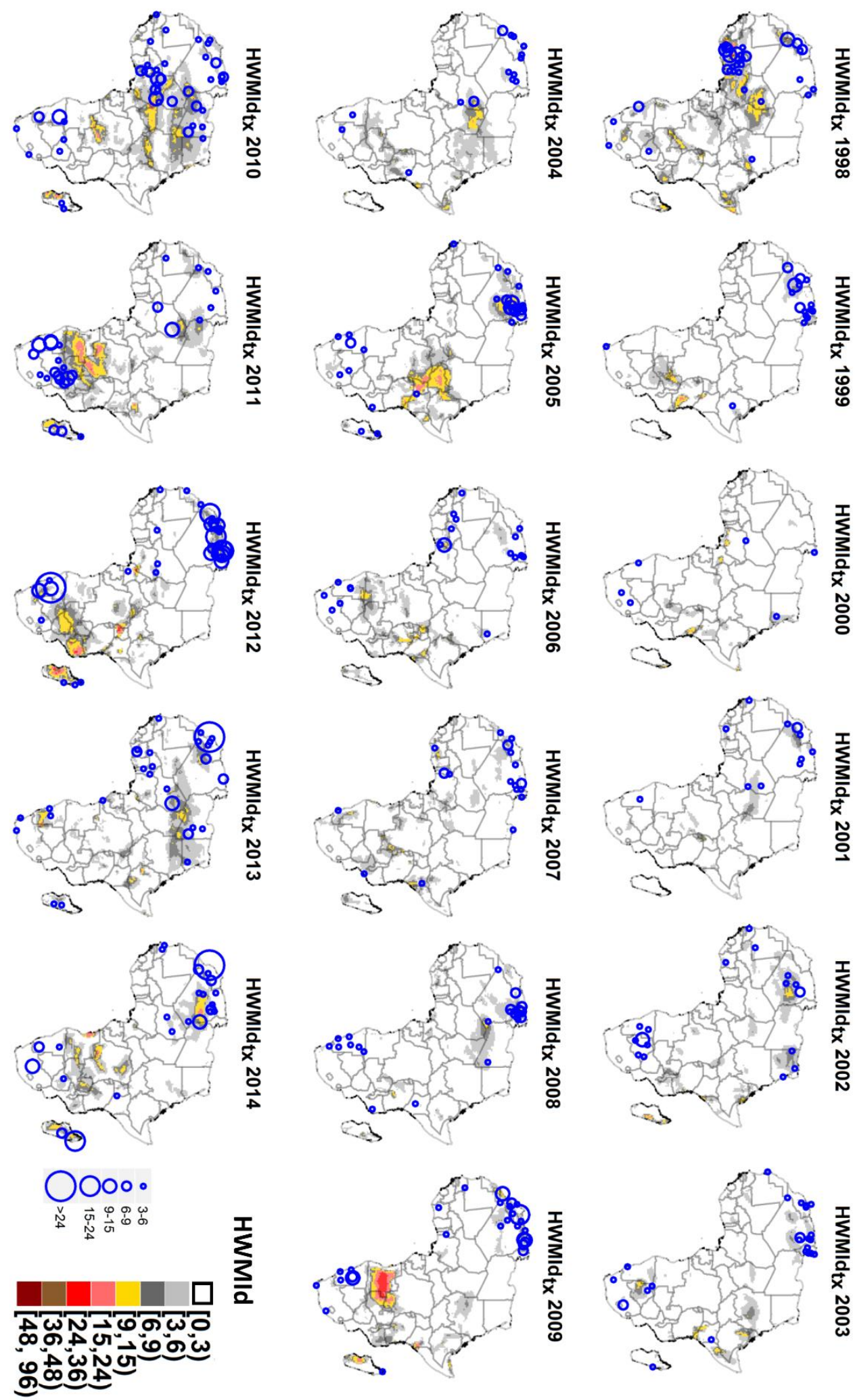

Figure S3 Visual comparison of HWMId detected by observation (blue circles) and reanalysis (gridded maps). 

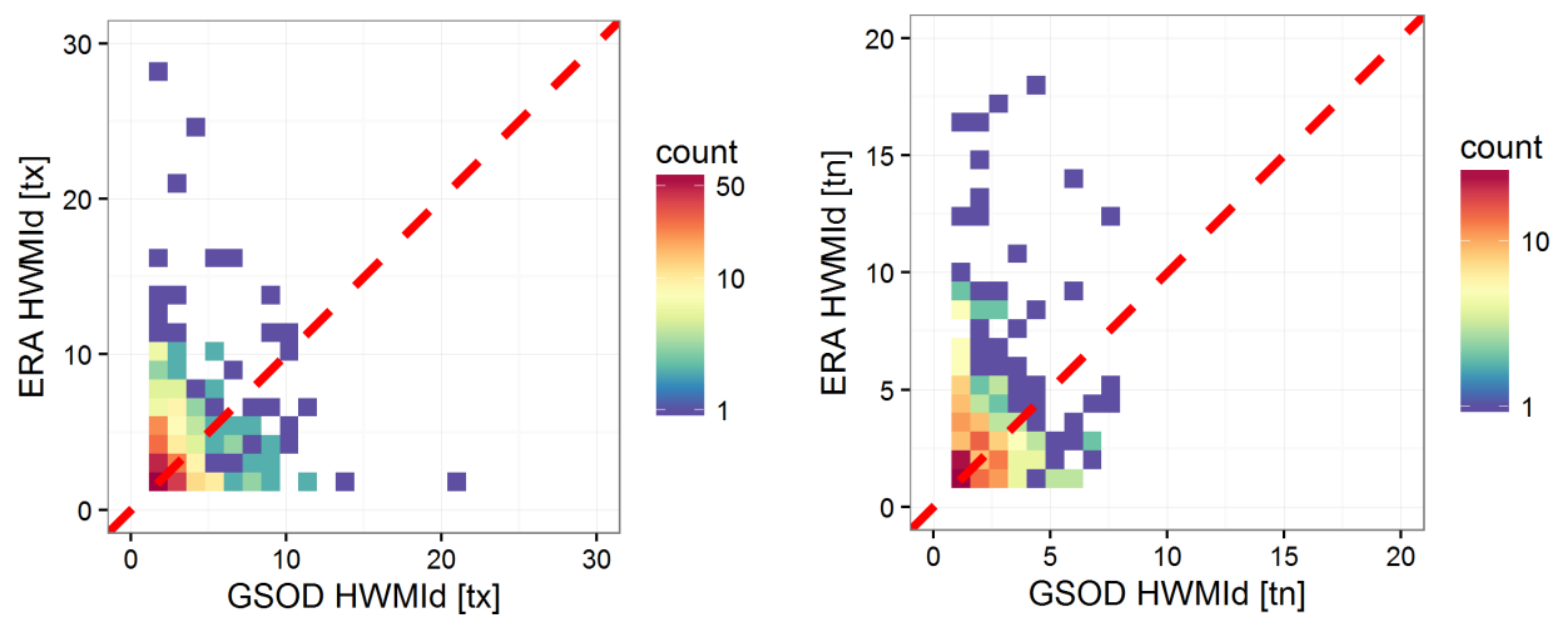

Figure S4 Scatterplot of HWMId detected by GSOD and ERA-INTERIM for maximum (left panel) and minimum (right panel) temperature.

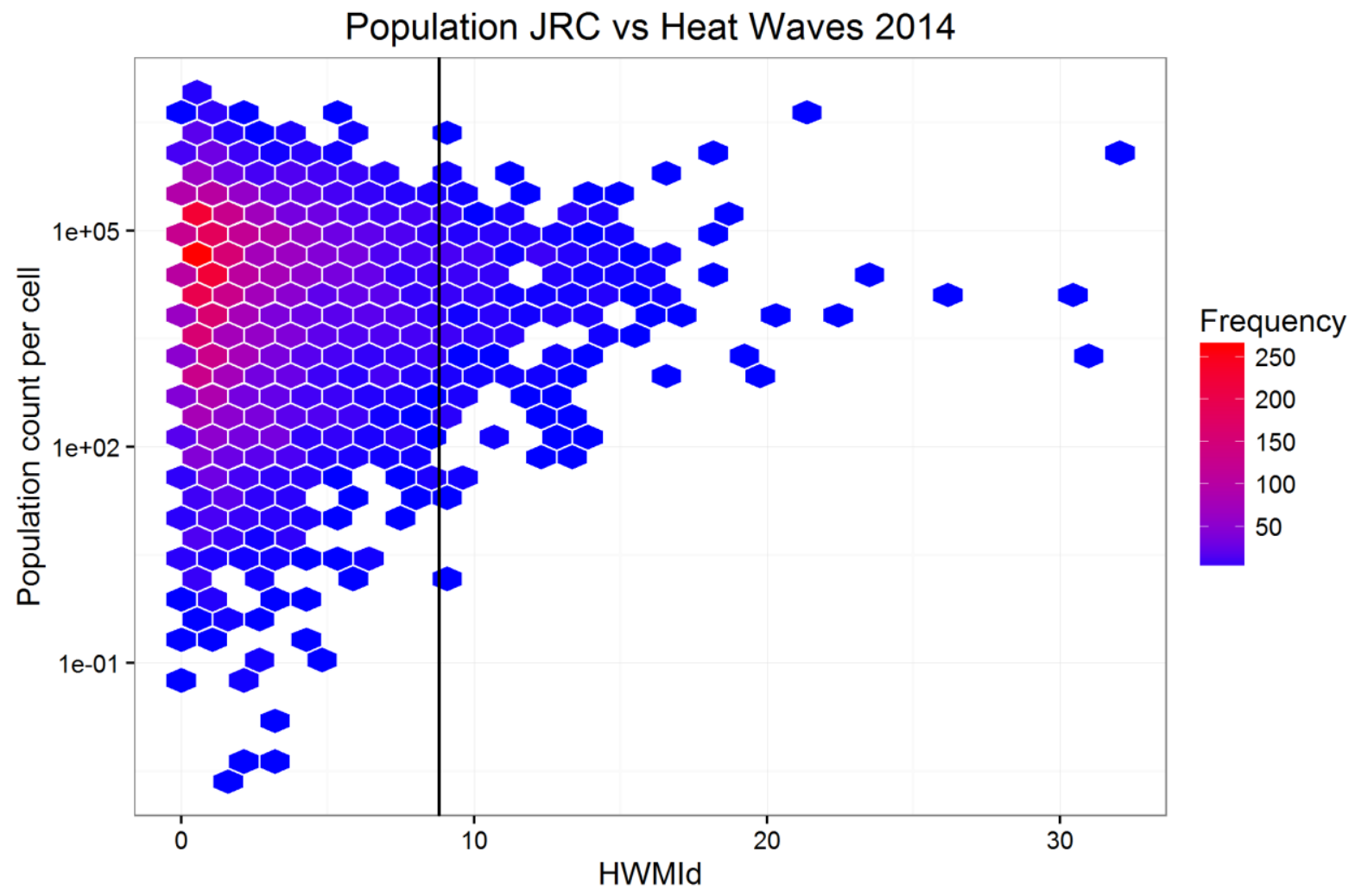

Figure S5 Density plot of population affected by heat waves of maximum temperature detected by reanalysis in 2014 using the Joint Research Centre Urban Settlement Layer. The y-axis refers to the population count per cell, where the cell is the $0.75^{\circ} \times 0.75^{\circ}$ ERA-INTERIM pixel. The black vertical line is at HWMId $=9$. 